\title{
CRISIS DEL DERECHO PENAL BURGUÉS \\ (un examen al carácter de clase del estado de derecho)
}

\author{
Crisis of the bourgeois criminal law \\ (An examination to the Rule of Law's class nature)
}

\begin{abstract}
"Se busca un Juez que ocupe el medio, entre las partes; $y$ a veces se da a los jueces el nombre de mediadores, como si estuviéramos seguros de haber encontrado la justicia, una vez que hemos hallado el justo medio".
\end{abstract}

Aristóteles

Ética a Nicomaco

\section{Oscar A. Fernández O.*}

\section{Sumario:}

1. Introducción. 2. La expansión del derecho penal: en defensa de un orden de clase. 3. La Democracia y la Ley. A manera de conclusión. 4. Bibliografía

Resumen. La visión burguesa acerca del delito común se ciñe estrictamente al acto violento cometido por uno o más individuos en contra de la propiedad o de la integridad física a terceros y su solución es de exclusiva responsabilidad del Estado, quien debe ejercer la violencia legal para controlarla o erradicarla, quedando la comunidad a merced de las medidas policiales y judiciales que se implementan para tal fin. El delito no es una anomalía, es el resultado insoslayable de la existencia del modelo de explotación y expropiación en la sociedad capitalista, que promueve un capitalismo salvaje.

El origen del delito es de carácter estructural, es inmanente al tipo de relaciones de propiedad, de producción y de intercambio que se dan dentro de ella. La reproducción del capitalismo se presenta no sólo como producción y distribución de mercancías, también como reproducción de individuos carentes de medios de subsistencia que se ven obligados a venderse al capitalista (y esto es necesario para la preservación del sistema) pero como no todos logran incorporarse al sistema productivo -ya que este es incapaz de absorberlos en sutotalidad-, se origina una "masa" de desposeídos (ejército de reserva los llamaba Marx) que no pueden garantizar en absoluto su existencia; esta "masa" privada de todo medio de subsistencia se ve empujada a saciar sus necesidades básicas de manera instintiva e inmediata; ya no se le presentan opciones entre lo correcto o no, lo deseable o no; ahora es un asunto de perentoria supervivencia del individuo, del marginado, del execrado del disfrute de la riqueza que produce la propiedad privada, obligándose a esa "masa" a delinquir.

Palabras clave: Derecho, Orden Jurídico, Estado de Derecho, Estado Democrático, conflicto social.

* Politólogo y Pedagogo. Catedrático- Investigador Universitario. Estudiante del Doctorado en CC SS. Universidad del Zulia, Venezuela. Universidad de El Salvador. jucarman.dez@gmail.com 
Abtract. The bourgeois vision of the offense adheres strictly to commonviolent act committed by one or more individuals against property or physical integrity of others and their solution is the sole responsibility of the State, who must use violence to control or eradicate legal, leaving the community at the mercy of police action judicial and implemented for this purpose. Crime is not an anomaly, is the inevitable result of the existence of the pattern of exploitation and expropriation of capitalist society, which promotes a savage capitalism. The origin of the crime is structural; it is inherent to the typeproperty relations of production and exchange that exist within it. The reproduction of capitalism has not only production and distribution of goods, as well as reproduction of individuals without means of subsistence are forced to sell to the capitalist (and this is necessary for the preservation of the system) but as not all manage to enter the productive system, as this is unable to absorb them into their-all, it causes a "mass" of the dispossessed (reserve army Marx called them) who cannot absolutely guarantee its existence, this "mass" deprived of all means of subsistence is driven to satisfy their basic needs instinctively and immediate and are not presented choices between right or wrong, desirable or not is now an urgent matter of survival of the individual, the marginalized, the execrated the enjoyment of the wealth produced private property, forcing the "mass "to commit crimes.

Keywords: law, legal system, rule of law, democratic state, social conflict.

\section{INTRODUCCIÓN}

El Estado de Derecho excede un simple conjunto de normas constitucionales y legales, pues involucra a todos los ciudadanos, no sólo a diputados que legislan o a políticos que gobiernan. La existencia del Estado de Derecho se mide en el funcionamiento de las instituciones y en la praxis política cotidiana. El Estado de Derecho suministra la libertad para el libre juego de pensamiento y acciones y debe permitir las modificaciones y cambio que el proceso social requiera. El Estado de Derecho excede el campo de lo jurídico para tocar el terreno de la política y la ética, pues existen derechos naturales inalienables. Así entendido, podemos hablar de un Estado Social Democrático de Derecho que comprende los derechos sociales de los cuales la población es titular y garantiza el ejercicio pleno de la democracia, reflejada en las leyes, la educación y la cultura.

Es obvia, entonces, la relación entre derecho y política. El derecho emana de la voluntad de los ciudadanos no de una élite económica, y el gobierno, expresión de esa voluntad ciudadana, está limitado en su acción por los derechos que esa voluntad encarna. El logro del bien común es el objetivo genérico del derecho. Si bien la democracia es una forma jurídica específica no puede limitarse a garantizar la alternancia en el poder de las diversas expresiones políticas, sino que debe avanzar en la institucionalización de principios y valores de justicia social distributiva. ${ }^{1}$

En este sentido, el principio de Estado Social de Derecho contrasta con el Estado de Derecho liberal en cuanto a sus fines: el Estado Social de Derecho ya no se limita solamente a asegurar la vida, la propiedad y la libertad mediante la protección contra el fraude, el hurto, el incumplimiento contractual o los daños ocasionados por terceros, funciones típicas del Estado gendarme. Sus fines tienen mayor alcance e incluyen, entre otros, promover la prosperidad general; garantizar la efectividad de los principios, derechos y deberes consagrados

\footnotetext{
${ }^{1}$ García, Jordi. Ética contrapolítica. Los intelectuales en el poder de Elías Díaz. 199o. Ed. Paidos, Barcelona. 
en la Constitución; facilitar la participación de todos en las decisiones que los afectan y en la vida económica, política, administrativa y cultural de la Nación.

El Derecho, para decirlo claramente, es un fenómeno politizado (es decir, de naturaleza política) pues dependerá del consenso alcanzado en democracia. En otras palabras los derechos sociales deben ser incorporados a los fundamentos del orden estatal mismo. Es esto lo que se llama Estado Social de Derecho y es lo que una democracia participativa en este siglo XXI debe profundizar, permitiendo que se plasmen en las conductas políticas democráticas de todos los días la mutabilidad y los desafíos relativos al bien común. Para ello debe crear canales donde fluyan las voluntades y se encaucen los procesos de desarrollo de las personas que constituyen todo el entramado democrático. Se requiere, pues, de una cultura política de la legalidad vista como la convicción de que no basta la existencia de un Estado de Derecho para que pueda hablarse de una sociedad justa, pues la sociedad justa sólo se alcanza en un Estado Social de Derecho. Al igual que debemos admitir que es en la democracia participativa, donde se puede proceder a distribuir la riqueza social.

La democracia está hecha de los materiales sociales que componen la sociedad llamada democrática. Las normas jurídicas no son legítimas sólo por su origen, fundamentalmente lo deben ser por sus efectos. El asunto es, pues, el papel del derecho (Rule of law) en la fundación y regulación de la democracia. La Constitución es el consenso sobre una concepción de la vida colectiva, es el contrato social. En nuestra sociedad no existe un compromiso hacia las reglas del juego democrático encarnado en el derecho, ni por parte del pueblo ni por parte de las autoridades. El Estado Social de Derecho implica principios éticos, jurídicos y políticos que deben tener eco en las decisiones judiciales que fomenten el respeto a las reglas fundamentales del juego político. ${ }^{2}$

\section{LA EXPANSIÓN DEL DERECHO PENAL: EN DEFENSA DE UN ORDEN DE CLASE}

No conocemos ni nos explicamos completamente nuestra existencia contemporánea, porque nuestra comprensión del pasado como del presente, se encuentra mitificada por una ideología (visión falsificada de la realidad) que nos miente y nos engaña constantemente y sólo sirve para preservar el orden económico-social, político-jurídico vigente. El orden de clase, en este plano y de acuerdo a una visión marxista de la conformación social, es la disposición en que se encuentra establecido el sistema de propiedad de los medios de producción, resguardado por una legalidad diseñada de manera ex profesa, para proteger los intereses de la clase dominante, en este caso la burguesía. Todo el ordenamiento jurídico del Estado, como instrumento de control de esta clase, está en función de lo anterior, aunque el discurso filosófico liberal apunte a la igualdad "frente a la ley".

Si se quiere eliminar la explotación y la opresión de nuestra realidad, debemos reflexionar críticamente y en forma activa acerca de nuestras propias opiniones y prácticas cotidianas,

\footnotetext{
${ }^{2}$ En el terreno teórico, las nociones de «ley» $\mathrm{y}$ «derecho» son tratadas (sin intención de entrar en discusiones de relativa profundidad), como el debate entre iusnaturalismo y positivismo jurídico a partir de nuestras visiones de sentido común hasta situarlas en una relación precisa con la política. Con este propósito, nuestra perspectiva de análisis del Estado de derecho lo vincula con problemas de fundamentación moral y política que muchas veces quedan fuera de los enfoques que se limitan a lo jurídico. Ésta es la razón por la que, una vez que entramos en el terreno legal, nos quedamos en el nivel que más admite una lectura política y social: la teoría constitucional, nivel que es, por lo demás, la forma de presentación moderna de la figura del Estado de derecho. (Ver Estado de Derecho y Democracia. Jesús Rodríguez Zepeda. Cuadernos de divulgación de la cultura democrática. Instituto Federal de México. Cap. III: Kant. Ética y Estado de Derecho)
} 
comprendiendo dialéctica e históricamente la cosmovisión del mundo que nos rodea. Marx, precisa que: "No es la conciencia del hombre la que determina su ser, sino, por el contrario, el ser social es lo que determina su conciencia"., 4

En tal sentido, debemos entender que cualquier posibilidad de una vida distinta resultará únicamente de nuevas ideas que se formen cuando modificamos nuestra concepción de la realidad y de nuestro modo de vida, siendo necesario para ello un nuevo punto de partida intelectual, espiritual, político, comprendiendo que son los pueblos quienes hacen su historia por su acción según su voluntad, que es la expresión de sus ideas (ideología), las que proceden de sus condiciones de existencia material, de su pertenencia a una clase. Por lo que, solamente con una explicación teórica de nuestra práctica y de nuestras ideas podremos empezar a construir un país mejor. Estamos obligados, si nuestro objetivo es liberarnos, a crear pensamiento alternativo, coherente y correspondiente con la época histórica que nos ha tocado vivir.

En el campo del régimen legal, nuestro pensamiento se limita a confirmar una ideología del establishment que respalda el orden social y económico vigente (statu quo) Mientras no se comprenda la naturaleza del derecho en la sociedad capitalista neoliberal, seguiremos sujetos a una realidad opresiva. De lo señalado diremos entonces, que, se necesita una filosofía crítica-marxista del orden legal imperante, que permita encarar y procurar el logro de una nueva realidad.

Únicamente con una comprensión real del significado del orden legal, a través de una Teoría crítica dialéctica e histórica, será posible superar el presente y crear una existencia alternativa al orden imperante de los grandes capitalistas, por cuanto, el objeto final de una filosofía crítica del orden legal, es la liberación que se logrará a través de una crítica de una acción revolucionarias de los seres humanos, permitiéndonos salir de esta manera de la ideología burguesa y de sus condicionantes.

El Derecho Penal capitalista, por sí solo, como lo hemos dicho en ocasiones anteriores, protege a una minoría de la población: a los explotadores, a los detentadores del poder económico y político y por ende propietarios de los medios de producción, en desmedro de las grandes mayorías, carentes de bienes y propiedad privada de los medios de producción, y que solo son dueños de su fuerza de trabajo (desocupados, explotados, oprimidos, pobres, excluidos sociales), impidiendo así el sistema jurídico que las clases desposeídas adquieran poder, o mejor dicho lo ejerzan ya que les corresponde históricamente. ${ }^{5}$

\footnotetext{
3 Marx, C. Contribución a la crítica de la Economía Política. Ed. Siglo XXI. 1980

${ }^{4}$ En un estado determinado de su desarrollo las fuerzas productivas materiales de la sociedad entran en contradicción con las relaciones de producción existentes o -lo cual sólo constituye una expresión jurídica de lo mismo- con las relaciones de producción dentro de las cuales se habían estado moviendo hasta ese momento. Al considerar esta clase de trastocamientos, siempre es menester, distinguir entre el trastrocamiento material de las condiciones económicas de producción, fielmente comprobables dentro de las ciencias naturales, y las formas jurídicas, religiosas, políticas, artísticas o filosóficas, en suma ideológicas, dentro de las cuales los hombres cobran conciencia de este conflicto y lo dirimen. (Karl Marx. Contribución a la Crítica de la Economía Política. 1859)

5 Parece obvio que el derecho penal del enemigo realiza una demonización de determinados grupos de infractores, esto es, es un derecho penal de autor y no de hecho. Si observamos nuestra legislación penal en materia de terrorismo, el "estar ahí" de algún modo, "formar parte" de alguna manera, "ser uno de ellos", aunque solo sea ideológicamente, es suficiente. En este sentido se pronuncio acertadamente el jurista chileno Juan Bustos, al afirmar que la legislación antiterrorista "no está dirigida a hechos determinados, sino a sujetos determinados, a los terroristas, con lo cual ya el principio básico del derecho penal como un derecho sobre hechos y no sobre autores, resulta afectado". Comparto la idea defendida por este autor de que la idea de partida de esta legislación se basa en una relevancia total del aspecto subjetivo, lo que produce una división 
La aparente contradicción prevención - represión, no es el fracaso del sistema penal que confía más en la represión, sino en las groseras contradicciones y desigualdades que presenta nuestro proceso social, exacerbadas por una estrategia neoliberal extremista que descarta el bienestar social, aumenta la exclusión y potencia la concentración de la riqueza. La policía no es un hecho metafísico, sino que político; no es una institución simplemente del Estado, sino siempre de un determinado Estado. ${ }^{6}$

En otras palabras diríamos que tener fe ciega en los parámetros legales estipulados por el Derecho penal, y aceptar la explicación y descripción de los fenómenos del crimen y la violencia generalizada, sin el mayor análisis crítico es caer en una postura subjetiva y dogmática, al creer en la "cientificidad" de esta perspectiva de estudio del delito, de tendencia técnico jurídico y acrítica.

Las tasas de criminalidad de cualquier Estado también constituyen un índice de la medida en que la clase dominante, a través de su aparato de derecho punitivo, debe ejercer su coerción sobre el resto de la población evitando de esa manera cualquier amenaza a su capacidad de poder y poseer. Así, la ley penal como medio de coerción para el establecimiento del orden interno en interés de la clase dominante, se convierte en una premisa fundamental de la crítica radical sobre el crimen.

En El Salvador impera un capitalismo selectivo en donde no hay una economía abierta a los más pobres que son la mayoría, sino abierta a la globalización y a la especulación del capital transnacional, esto se explica debido a que existe una mala e injusta distribución de la riqueza social, de la renta nacional per cápita y tiene como complemento un alto índice de desempleo y más del 40\% de subempleo o empleo informal. Con la desregulación del trabajo laboral se ha intensificado la explotación del trabajo sobre todo juvenil, incrementando la pobreza, la desocupación y la exclusión social, favoreciéndose los grandes señores capitalistas dominantes.

Esto ha demostrado en los hechos que el neoliberalismo como respuesta a la crisis de desarrollo, no sólo ha sido incapaz de resolver las necesidades básicas de la población como: salud, educación, trabajo, etc., sino que por el contrario ha agudizado las enormes diferencias existentes en nuestra sociedad actual, haciendo más pobres a los pobres y enriqueciendo más a los ricos todo por su afán de acumular más riqueza. Es un modelo basado en la violencia, que por lógica engendra violencia.

Comprender que el sistema legal no está al servicio de la mayoría de la población nacional, sino de los intereses de la clase dominante, es el punto de partida de una comprensión reflexiva, crítica y radical del derecho penal en la sociedad capitalista neoliberal.

"La clase dominante logra mediante su empleo del sistema legal preservar un orden interior que permite a los intereses económicos dominantes conservarse y promoverse. La clase

entre amigos y enemigos. Esto es, el terrorista deja de ser un ciudadano más y pasa a ser un enemigo. (Juan Fernández Requena. Terrorismo en el Derecho Penal del Enemigo. Universidad de Valencia. España, 2001)

${ }^{6}$ Bajo el impacto de la mundialización del capitalismo y las nuevas relaciones económicas y sociales que ésta genera, nuestras ciudades deshacen las antiguas relaciones culturales, comunitarias y religiosas, y precipitan a los habitantes a relaciones cada vez más difíciles y agresivas suscitadas básicamente por la exclusión de cada vez mayor cantidad de personas. "La juventud ha sido anatemizada y convertida en objeto de miedo. Los adultos tratamos de beneficiarnos de la impunidad, y cada uno siente que los valores de la vida social están siendo cuestionados más gravemente por estas faltas de civilidad que por el delito mismo (Michel Marcus. El delito y la regulación de conflictos urbanos. ILANUD, Ed. Siglo XXI. 1997) 
dominante sin embargo, no ejerce el control directo del sistema legal, sino que debe operarlo a través de los mecanismos del Estado". ${ }^{7}$

La visón burguesa acerca del delito común se ciñe estrictamente alacto violento cometido por uno o más individuos en contra de la propiedad o de la integridad física a terceros y su solución es de exclusiva responsabilidad del Estado, quien debe ejercer la violencia legal para controlarla o erradicarla, quedando la comunidad a merced de las medidas policiales y judiciales que se implementan para tal fin. El delito no es una anomalía, es el resultado insoslayable de la existencia del modelo de explotación y expropiación en la sociedad capitalista, que promueve un capitalismo salvaje. ${ }^{8}$

El origen del delito es de carácter estructural, es inmanente al tipo de relaciones de propiedad, de producción y de intercambio que se dan dentro de ella. La reproducción del capitalismo se presenta no sólo como producción y distribución de mercancías, también como reproducción de individuos carentes de medios de subsistencia que se ven obligados a venderse al capitalista (y esto es necesario para la preservación del sistema) pero como no todos logran incorporarse al sistema productivo -ya que este es incapaz de absorberlos en su totalidad-, se origina una "masa" de desposeídos (ejército de reserva los llamaba Marx) que no pueden garantizar en absoluto su existencia; esta "masa" privada de todo medio de subsistencia se ve empujada a saciar sus necesidades básicas de manera instintiva e inmediata; ya no se le presentan opciones entre lo correcto o no, lo deseable o no; ahora es un asunto de perentoria supervivencia del individuo, del marginado, del execrado del disfrute de la riqueza que produce la propiedad privada, obligándose a esa "masa" a delinquir.9

El drama histórico de nuestro tiempo es que la burocracia del Estado y el sistema político corrupto, debaten acerca del delito y sus consecuencias, logrando que pase desapercibido el carácter de clase capitalista del Estado, su verdadero fundamento o contenido social. El Estado de los hombres más ricos ha planteado el debate en términos que nada tienen que ver con la supuesta defensa de los derechos de la "ciudadanía" o de los "intereses generales" de las "personas", ni con los derechos históricos nacionales, sino con el dominio o la decisión de rescatar y fortalecer el modelo neoliberal y perpetuar una sociedad excluyente, necesaria

7 Elena Larrauri. La herencia de la criminología crítica, ed. Siglo XXI, 2da. Edición. México.

8 Adicionalmente, de acuerdo con Ferrajoli, para que una pena esté justificada debe probarse que cumple con las finalidades antes expuestas. En este sentido Ferrajoli (1995: 325) distingue doctrinas de justificación (criterios valorativos que sólo pueden rebatirse con argumentos normativos) y justificación (comprobación empírica de los fines preconizados). Entiendo como un avance de la teoría de Ferrajoli que no declare la pena justificada hasta que no se pruebe empíricamente la correspondencia entre el fin que debe servir y la función que efectivamente cumple, superando con ello la creencia de que basta la alegación de la prevención de delitos para creer que la pena está justificada (falacia normativista). Elena Larrauri. Criminología crítica: Abolicionismo y garantismo. Estudio realizado en 1998, presentado en la Facultad de Derecho, Universidad de Medellín.

9 Zaffaroni, lo explica de esta forma que comparto en otro trabajo que publiqué: "En la teorización de la política criminal, siempre se postularon mayores cuotas de represión para los crímenes más graves, incluso, desde las posiciones más radicalizada. Además, casi siempre se ha teorizado una represión diferente para los no molestos (a la policía) y otra para los molestos, destinando, para los últimos, medidas de segregación o eliminatorias, desproporcionadas con la gravedad de las infracciones cometidas. En consecuencia, no es ninguna novedad que se teorice una represión penal plural: por un lado, para los patibularios (¡Mátenlos!) y para los locos y molestos (¡Fuera de aquí!), y, por otro, para los ocasionales (Gente más parecida a uno, que se equivoca)” Zaffaroni, Eugenio. La legitimación del control penal de los “extraños”. Publicado en www.neopanopticum. wordpress.com, agosto de 2008. 
para el desarrollo del mercado que se sustenta en la desigualdad. Un Estado que se defiende de sus "nuevos enemigos"."

En El Salvador, la reforma penal ha traído más confusión que efectividad, puesto que el liderazgo político no termina de digerir que en una democracia real la institución policial cambia el viejo concepto clasista burgués por el de servicio público, obligándola a proteger los derechos de los ciudadanos y a descubrir la mayor cantidad de delitos, para que el sistema penal cumpla con mantener la criminalidad dentro de límites socialmente tolerables.

La problemática de la criminalidad es un asunto complejo, que debe ser abordado de manera sistemática y multifactorial, hemos insistido en ello. Aun así, es una utopía pretender erradicar la delincuencia, porque es consustancial al conglomerado social. Sin embargo, es factible aspirar a una reducción de sus cifras. El cumplimiento de este objetivo está condicionado a la sensatez de las soluciones propuestas desde la política criminal estatal. Si se opta por soluciones inadecuadas, el problema, lejos de disminuir, sin duda aumentará pasando de formas simples a formas mucho más complejas, pues sus efectos se acumulan y se convierten en causas.

El triángulo policía - justicia penal - cárcel se ha demostrado impotente. Tenemos la Policía con el mayor presupuesto de Centro América y la delincuencia continua sin presentar una reducción alentadora. A la Fiscalía se le ha otorgado el monopolio en la investigación criminal y sin embargo su fracaso es manifiesto. El problema de los reclusorios y centros de detención es ya impresentable.

Para ser efectivos contra el delito no necesitamos transformar a la Policía en un suprapoder justiciero o en un súper ejército armado hasta los dientes, ni convertir el país en un gigantesco campo de detención, dónde todos seremos culpables hasta que no probemos lo contrario. Lo que la Policía debe hacer es depurarse, especializarse, prepararse y reorganizarse en función de una mayor exigencia para enfrentar adecuadamente nuevas y mucho más complejas modalidades del crimen callejero y del gran crimen organizado, que ha sido "ignorado" por mucho tiempo.

El debate no ha perdido actualidad. Todo lo contrario. Todos los días seguimos encontrándonos con sectores del poder político que pretenden echar mano al derecho penal para "solucionar" conflictos. Por otro lado, seguimos encontrando justificaciones doctrinarias de esas prácticas.

Asimismo, en la posición contraria seguimos escuchando, cada vez con mayor ahínco teórico, afirmaciones provenientes de grandes exponentes de la sociología y la criminología que pugnan por deslegitimar la expansión normativa llevando las cosas a estadios exorbitantes. De ahí la insistencia por nuestra parte de seguir investigando, acerca de los verdaderos límites del poder punitivo del Estado. Límites estos, que se intentarán buscar en los dos sentidos posibles, es decir, buscando el mínimo de conductas que deben estar previstas por las

\footnotetext{
${ }^{10}$ Si la cúspide de la civilización fue alcanzada a través del actual sistema capitalista, cuyos mejores tesoros a mostrar son su democracia representativa, su positivización de los derechos humanos y su derecho penal y procesal penal respetuoso de las garantías individuales ¿Cuál es el motivo de las continuas violaciones de esos derechos humanos? ¿Cuál es la necesidad permanente de recurrir a legislaciones de excepción que "limiten", "restrinjan", "suspendan" determinadas garantías individuales? ¿Por qué se deja de lado el tan laureado Estado de Derecho y se legisla respondiendo a coyunturas, con una clara tendencia a ganar rédito político y no de garantizar la justicia? El Derecho Penal del Enemigo, sostienen Riquert y Palacios, surge como una postura teórica en la dogmática penal que justifica la existencia de un derecho penal y procesal penal sin las mencionadas garantías. Uno de sus sostenedores es el pensador alemán Günther Jakobs, quien a los fines de construir su teoría del delito se basa en el estructuralismo-funcional de Luhmann. Revista La Ley. www.scrbd. com
} 
leyes penales como así también los límites sobre lo máximo que pueda penarse de acuerdo a las exigencias de justicia. En otros términos, intentaremos buscar los límites de un derecho penal justo, que sancione aquello que por lógica debe ser sancionado, pero deslegitimando aquella intervención estatal que, so pretexto de "necesidades político-criminales", configure un arbitrario ejercicio del ius puniendi. ${ }^{11}$

Es lamentable que pretendidas políticas civilizatorias y digamos modernas en materia de seguridad pública, sean víctimas de un cuestionamiento superfluo e ideologista y terminen siendo orientadas a la utilización del derecho represivo frente a la ocurrencia de los múltiples conflictos sociales. El Estado y sobretodo los legisladores no deben continuar concibiendo la función policial como exclusivamente represora del crimen y a la policía como una agencia estatal destinada sólo a la ejecución de la norma penal.

En otro plano, una afligida sociedad se pregunta cómo después de firmada la paz, veinte años de gobiernos ultraderechistas han propiciado un tremendo fracaso frente al avance del crimen y de la impunidad, permitiéndoles incrustarse en nuestro imaginario social con la categoría de cultura.

La respuesta está en una visión simplista de las causas del delito y en la falta de capacidad para reconducir a la policía, la cual evidencia ya un deterioro que la desvía de los propósitos trazados por los Acuerdos de Paz. Es posible que hace quince años hayamos pensado, consciente o inconscientemente, en una policía para controlar delitos manifiestos contra los bienes y el mantenimiento del orden público, pero ahora, frente a nuevas formas de criminalidad, debe adoptarse otro modelo psicológico de selección policial y sin duda, de profesionalización y organización.

Si la nueva realidad nos demanda construir un Estado democrático dónde el Derecho no sólo sea norma sino un límite del poder y la característica sea eficacia y sabiduría para gobernar respetando las libertades, no nos escudemos culpando al Derecho de nuestra incapacidad de entender la democracia, porque en el principio de este mito se encuentra la mentira que legitima a los tiranos.

La maquinaria punitiva del Estado se ha visto incrementada cuantitativa y cualitativamente desde hace ya tiempo. Esta incrementación se produce, obviamente, en el plano de lo que la doctrina más popular denomina "criminalización primaria”. Pero en el plano de la

\footnotetext{
${ }^{11}$ Lejos están los legisladores de tomar en cuenta la verdadera causa de la delincuencia y de programar soluciones, sostiene Leonardo Schonfeld. "La mayoría de ellas a largo plazo, que puedan solucionar el problema. Es más fácil recurrir, con la confianza legalista propia de un racionalista, a las leyes; como si el Código Penal pudiera cobrar vida y, por sí mismo, saliera a reprender delincuentes. El estúpido e infantil idealismo maltrae a quienes expanden el derecho penal. Surge entonces la inevitable pregunta: ¿No atentan estas inflaciones contra un Derecho que verdaderamente respete el mínimo de libertad de que la naturaleza humana es digna? La respuesta es inevitablemente afirmativa. Pero debe ser un poco más reflexiva. Veamos. La inflación penal existe, de eso no cabe duda. Pero ese "hecho" inflacionario puede tener diversas motivaciones, según sea la ideología que lo inspire. En un sentido contrario, la tentativa de limitar al poder punitivo del Estado puede provenir de distintas ideologías que, con fundamentos diferentes y partiendo de diferentes postulados, lleguen a la misma conclusión. Es decir, y valga como ejemplo: Un legislador presenta un proyecto de ley propugnando una reforma al Código Penal introduciendo la pena de "castración" frente al aumento de delitos violación. Pero debe advertirse que esta actitud legislativa vino provocada por los parciales medios de comunicación que "mediatizan" casos previamente seleccionados de entre una enorme cantidad de delitos que se cometen a diario. Así, la expansión del derecho penal se debe, de manera mediata, a los intereses de los medios de comunicación. La mecánica es simple: se cometen delitos de toda indole de los cuales los medios seleccionan los más "relevantes", generando una "sensación de inseguridad" en la sociedad respecto de la comisión de esos delitos. (Schonfeld, Leonardo. La expansión del derecho penal como política demagógica, 2da. Parte. Derecho Penal y Criminología Latinoamericana. 2010)
} 
criminalización secundaria la situación es la inversa. Nos encontramos con la imposibilidad física de canalizar todo aquello que se "criminaliza” primariamente. Las razones por las cuales estas agencias de criminalización secundaria se ven imposibilitadas de acarrear con aquél aumento desmedido de la incriminación legislativa, pueden obedecer, según creo, a dos factores.

Por un lado, existe una "intrínseca ineptitud operacional" para concretizar la amenaza de pena concebida teóricamente de modo abstracto. Es decir, las agencias secundarias no tienen el "poder" para detectar ciertos delitos entre los que se encuentran los más relevantes en el contexto actual latinoamericano. Vale poner como ejemplo, la enorme cantidad de delitos económicos y de corrupción, cuya investigación prácticamente se obvia o se encarga a ciertas instituciones secundarias que por la propia génesis del sistema político se ven imposibilitadas para detectarlos. Por otro lado, nos encontramos frente a una criminalización primaria tan ilusa, simplista y demagógica, que echa mano al Código Penal para solucionar problemas que deben ser resueltos en otro plano.

El proceso penal no puede ignorar ciertos principios rectores de carácter constitucional. Es de interés de la sociedad que los delitos sean sancionados, pero también lo es, el que en la administración de justicia prevalezcan la verdad y el derecho. Es fundamental para la colectividad que tanto la investigación como el procedimiento penal se lleven a cabo sin menoscabar los derechos fundamentales de las personas.

El proceso penal busca descubrir la verdad de lo sucedido con relación al delito o delitos que se investigan, y el instrumento jurídico para realizarlo es la prueba. "La prueba (del latín probandum, hacer patente, mostrar) es una constatación de hechos". Cabe señalar que lo relativo a la subjetividad de la prueba es conocido también como onus probandi o la incumbencia del probar. Ello presupone responder a la pregunta ¿cuál de los sujetos procesales debe producir la prueba de los hechos en litigio? ${ }^{12}$

En atención al interés público que supone la materia penal, un importante porcentaje de la actividad probatoria se encuentra a cargo del Estado, que de modo imparcial debe tratar de reconstruir los hechos para encontrar la verdad. Los demás sujetos procesales tratarán por su parte de presentar elementos o medios probatorios que apoyen sus intereses particulares. ${ }^{13}$

Debemos señalar que, de acuerdo a lo anterior, en el proceso penal lo relativo al principio de la carga de la prueba no tiene mayor impacto ya que al imputado se le debe reconocer jurídicamente su inocencia y esto trae aparejada la no-exigencia u obligación de demostrarla. ${ }^{14}$

En El Salvador, la reforma Constitucional establece que la Fiscalía General es la responsable de la prueba, lo que vulgarmente significa la condena del imputado. Desde mi punto de vista como politólogo, es decir desde la función política del Derecho, es un error considerar que le corresponda al Ministerio Público Fiscal la carga de la prueba, puesto que su interés no es condenar sino representar fielmente los intereses de la sociedad. Es el litigio entre el pueblo salvadoreño versus él o los imputados. ${ }^{15}$

\footnotetext{
${ }^{12}$ Hernández Pliego, Julio Antonio. Programa de Derecho Procesal Penal, Editorial Porrúa, México, 2002.

${ }^{13}$ Celia Blanco Escandón. La prueba y los Derechos Humanos. Universidad Latina de América. Sede México.

${ }^{14}$ Granfeld, David, "Justicia: El Corazón del Derecho. Universidad Iberoamericana, México.

${ }^{15}$ Para evaluar y proyectar el trabajo de la Fiscalía General de la República -FGR- se debe de partir de su papel constitucional específico como operador de la Administración de Justicia, la cual es un sistema de responsabilidad compartida, cuyo eficaz funcionamiento depende de la forma y medida en que se coordínenlos roles de cada uno de los sujetos que participa en la misma; el papel y responsabilidad fundamentales de la FGR se
} 
Por ello es que nos atrevemos a afirmar, que el deber real de investigar debe corresponder al Poder Judicial, a través de atribuciones en materia probatoria que podrá ejercitar tanto en la etapa de la instrucción como durante el juicio mismo. Las pruebas se apreciarán por el tribunal según su libre convicción, observando las reglas de la lógica, los conocimientos científicos y las máximas de experiencia. Alejarse de dicho principio puede conducir a la violación de garantías individuales. ${ }^{16}$

La posición del imputado dentro del proceso penal ha sido desde sus orígenes, motivo de controversia. El dilema ius puniendi versus ius libertatis ha estado presente a lo largo de la historia y de la evolución de las ideas penales y no ha sido siempre resuelto de igual manera. Tenemos planteamientos que van desde la sobrevaloración, por ejemplo, de la prueba confesional que legitimaba incluso al uso de la tortura como un instrumento procesal válido para obtenerla, hasta el reconocimiento de un estado de inocencia garantizado por cada una de las etapas procesales así como por una gama de principios que tutelan los derechos del acusado. ${ }^{17}$

El sistema probatorio adoptado en el proceso penal centroamericano constituye un termómetro del nivel de desarrollo democrático de una concreta comunidad. La relación entre proceso penal y sistema constitucional es excepcionalmente evidente al observar cómo los principios básicos que inspiran la justicia penal deben obtener una referencia en la carta política. En realidad el régimen procesal es reflejo fiel del sistema político, y da más o menos atribuciones al juez, a la defensa y a los ciudadanos, según el sistema político imperante. ${ }^{18,19}$

A pesar de ello, los ciudadanos alarmados por el constante incremento de las actividades criminales reclaman un cambio hacia una postura más represiva y dura del sistema penal. La mejor forma de combatir los abusos y la represión en materia penal continúa siendo la de limitarlos mediante la protección de los derechos inalienables de los seres humanos. Los poderes probatorios no deben conducirnos al autoritarismo. El buen criterio judicial, al resolver sobre la responsabilidad penal de una persona, se debe apoyar en el respeto por parte del Estado a la dignidad e integridad del ser humano, sino se profundiza la victimización y la violencia crece, impulsada por un efecto paradójico del Derecho Penal clasista.

ubica en la promoción de la acción penal pública y en la investigación y persecución del delito. (Ortíz Ruiz, Eliseo. Diez Tesis para un Debate sobre la Fiscalía General) www.eliseo-ortiz.blogspot.com

${ }^{16}$ Azuela G., Mariano. Derecho, Sociedad y Estado. Universidad Iberoamericana, México, 1996.

${ }^{17}$ Binder, A. Justicia Penal y Estado de Derecho. La justicia penal a las puertas del siglo XXI. 2004

${ }^{18}$ Daniel González. Presidente Sala Casación. Costa Rica, www.cienciaspenales.org.cr

${ }^{19}$ Se destacan tres grandes irregularidades del proceso inquisitivo muy conocidas y debatidas que los penalistas, estén de acuerdo en las siguientes, que alimentaron la necesidad de una reforma constitucional:

1. La confusiones de funciones investigativas, acusatorias y judiciales en los fiscales fundamentadas en el afán de aplicar una justicia retributiva.

2. La falta de publicidad del proceso penal por el enorme compromiso de lo escrito sobre lo oral en el proceso penal.

3. La irrelevancia del juicio oral en la medida que los procesos criminales en el país se deciden en la parte sumarial o fase de investigación. (Álvaro Cárdenas. La justicia restaurativa vs. La justicia retributiva en el sistema penal acusatorio. Prolegómenos- Derechos y Valores. Bogotá, D.C., Colombia - Volumen X - № 20 Julio - Diciembre 2007.) 


\section{LA DEMOCRACIA Y LA LEY. A MANERA DE CONCLUSIÓN}

La mayoría de las personas piensan que las leyes sirven para poco, sobre todo cuando en este país los primeros en hacer que se cumplan se encargan de violarlas a su antojo, fomentando y diseminando la corrupción como forma de manejar el Estado y por su lado, los que deben aplicarlas parecen no estar capacitados ni profesional ni éticamente, salvo contados políticos, funcionarios y jueces capaces y valientes, que son la excepción que confirman nuestras bizarras reglas del "juego social".

El escepticismo y la suspicacia de la población respecto a la efectividad de la protección legal en nuestro país, no carece de justificación. Esto ocurre porque la concepción del derecho ha cambiado y la ley no ofrece garantías ni se demuestra efectiva para todos. Lo cual se ha convertido en una "razón de peso" para los que detentan el poder, para argumentar que la ley de la sociedad debe ser suplantada por la ley del mercado, es decir, la ley de los iguales por la ley de los desiguales, dónde unos pocos controlan el poder y otros muchos sufren las brutales consecuencias de este abuso.

No obstante hay que mantener la resistencia a esa forma de usurpar el poder colocando el dedo en la llaga, porque la ley no sólo es la norma general cuyo cumplimiento es exigido por la autoridad, sino es el sentido de justicia de la sociedad hecha norma, como afirma N. Bobbio $^{20}$

En nuestro país los legisladores evidencian desde hace mucho, una manía por hacer leyes es decir, nos han llevado a una "inflación" de leyes lo cual desacredita al verdadero espíritu del Derecho y degenera el Estado de Derecho. Parece que nuestra suerte hoy depende más de la capacidad o incapacidad del legislador, del funcionario público o del abogado que de la Justicia.

Pero no sólo es la avalancha de leyes lo que disminuye el valor del Derecho, es también su mala calidad, porque a los diputados de la derecha poco les importa la congruencia con el Derecho (incluso lo ignoran) e imponen su voluntad mediante normas confusas que no pueden aplicarse con carácter general, favoreciendo sectores poderosos y destruyendo la naturaleza misma de la ley. La Constitución (por lo menos en teoría) no encomienda la labor de cambiar las leyes a su antojo, sino de evitar que cualquier poder lo haga así. Los parlamentarios no pueden sustituir a los juristas, porque no lo son. Los parlamentos del pueblo no fueron concebidos cómo máquinas productoras de leyes.

Sería enteramente gratuito tratar de identificar (o confundir) este concepto de Estado de Derecho con el concepto de Estado democrático, tan gratuito como sería suponer (como parecen suponerlo nuestros «armonistas éticos» de inspiración krausista) que el Estado de Derecho es un Estado que ha eliminado la violencia y la pena de muerte, como si el derecho no implicase por sí mismo la violencia y como si la pena de muerte no figurase en las constituciones de la mayor parte de los Estados de Derecho de nuestro presente. En efecto, el Estado de Derecho puede considerarse realizado también en una sociedad política fuertemente jerarquizada, aristocrática, por ejemplo, y, en todo caso, no parlamentaria, pero provista de un ordenamiento jurídico prácticamente omnicomprensivo (total) al que hubieran de ajustarse los miembros de la «nomenclatura», y que podría incluso comprender las más sutiles garantías constitucionales de la «libertad personal» (independientemente del estamento o clase social del que el individuo forme parte). Cabe inferir además que un Estado de Derecho aristocrático tendrá muchas posibilidades en sociedades políticas comparativa-

\footnotetext{
${ }^{20}$ Bobbio, Norberto. Igualdad y Libertad, ed. Paidos, Barcelona, 1985.
} 
mente sencillas, desde el punto de vista del desarrollo económico y tecnológico; en sociedades pre estatales, por ejemplo, las «formas elementales de parentesco» están mucho más normalizadas que en las sociedades constituidas como Estados. En cualquier caso, el Estado de Derecho de los doctrinarios alemanes estaba concebido en el ámbito de una monarquía hereditaria (no electiva); no contaba con el sufragio universal; el pueblo no era «el cuerpo electoral capitativo» que se reúne en asamblea, o por lo menos, nombra representantes parlamentarios, sino un pueblo concebido históricamente (como lo concibió Savigny), heredero de un derecho considerado sagrado, que se distinguía cuidadosamente de las leyes más o menos contingentes.

No es, por tanto, la transición a una democracia del voto por capitación el criterio que sirve para explicar el origen del Estado de Derecho, ni menos aún, el criterio para determinar el paso a una democracia efectiva. El concepto de Estado democrático no deriva del concepto de un Estado de Derecho. El criterio ha de tomarse de las transformaciones en la composición de las clases y grupos que constituyen la trama del conflicto social.

Es necesario entonces, destacar que resulta crucial rescatar el sistema de garantías constitucionales dado que nuestros derechos no son seguros frente a una concepción formal, positivista y manoseada de la ley, ni pueden estar sujetos a los intereses de clase de la plutocracia o gobierno de los ricos, que echan mano nuevamente del autoritarismo para imponer y defender su ideología de la desigualdad. ${ }^{21}$

El poder económico y sus voceros políticos, realizan una cruzada de "liberalización” del derecho, lo que demuestra el ataque contra el garantismo y la aplicación de un Derecho basado en los derechos humanos. Lamentablemente una sociedad poco educada y con tendencia al autoritarismo como la nuestra, está cayendo en la trampa. Recordemos como lo afirman los datos históricos, que la caída de la democracia griega comenzó cuando las personas fueron sometidas a leyes tan fácilmente cambiables y manipulables, que resultaron incapaces de asegurar la protección de los derechos.

Por ello como dice Norberto Bobbio: "La relación entre derecho y política se hace tan estrecha, que el derecho se considera como el principal instrumento mediante el cual las fuerzas políticas que detentan el poder dominante en una determinada sociedad ejercen su dominio". En este sentido, la relación entre derecho y política es vital para comprender los distintos modelos jurídicos y la lógica de sus transformaciones. ${ }^{22}$

\footnotetext{
${ }^{21}$ En cuanto al poder judicial, el contraste entre la Constitución (España 1978) y el Espíritu de las Leyes no puede ser más frontal. Sin perjuicio de la institución del jurado hay que decir que la idea del poder judicial utilizada de hecho tiene componentes fuertemente corporativos, como corporativo es el concepto de independencia del poder judicial que en este contexto se utiliza. (García S., Pelayo. Diccionario de Filosofía. Biblioteca Filosofía en Español. Oviedo, España, 1999. En www.filosofia.org

${ }^{22}$ En ese sentido, todos los autores que debatieron el derecho penal autoritario, afinaron y propugnaron reformas político-criminales, proponiendo alternativas al derecho penal vigente. La base de esas reformas consistió siempre en intentar limitar el poder punitivo, o la violencia aplicada legalmente por el Estado, mediante reglas racionales. Dando cuenta de ellas puede escribirse la historia del derecho penal liberal. En los últimos años, y a raiz de la crisis de confianza en los fines instrumentales de la pena, aquel derecho penal democrático ha resurgido con su finalidad limitadora del poder punitivo. Ante las dudas sobre la capacidad utilitaria de la pena (Garland 1999), las políticas criminales propugnadas por los autores democráticos han intentado basarse en la prudencia y en la limitación de la propia violencia estatal legítima. De esta manera, tales autores volvían sobre la senda del derecho penal liberal clásico expuesto ya en los textos de Beccaria, Kant o Carrara (Silva 1992:35). Ello puede observarse en los autores del área anglosajona y escandinava que se engloban en las teorías llamadas del just dessert (cuyo nombre hace hincapié en la proporcionalidad, pero que en teoría no olvida los otros límites), y también en los de lengua alemana (entre los primeros Von Hirsch 1998; entre los últimos Zipf 1980).' Sin embargo, han sido los autores italianos los que más directamente han influido para 
En el preámbulo de la Constitución francesa de 1791 se lee que los constituyentes han llegado a abolir "irrevocablemente las instituciones que herían la libertad y la igualdad de los derechos" y para recalcar ese propósito se afirma "Ya no hay, para ninguna parte de la Nación, ni para ningún individuo, privilegio o excepción alguna al derecho común de todos los franceses. Ya no hay cofradías, ni corporaciones de profesiones, artes y oficios. La ley ya no reconocerá ni votos religiosos, ni ningún otro compromiso que sea contrario a los derechos naturales o a la Constitución.”.

Sin embargo, el ideal de una sociedad que se organiza en Estado para que éste, sobre la base de una carta o gran pacto fundacional, sea el centro neutral que asegure los derechos y las libertades democráticas, aparece cada día como más lejano en el actual posmodernismo.

"El mundo postmoderno ha sufrido, en sus parámetros de razonamiento, un notable fenómeno: la cosificación del tiempo. En el milenio anterior, el tiempo era una circunstancia que acompañaba la realidad. Hoy, el tiempo es parte de una realidad, incluso como objeto prioritario. Las cosas no son las mismas según los tiempos que demoran, de modo tal que el tiempo es parte de la cosa". 23

Este razonamiento contemporáneo, traducido en la ansiedad del hombre moderno, se manifiesta en orden al derecho penal. La demanda de soluciones rápidas y eficientes, o, lo que es peligroso, eficientes porque son rápidas, ha repercutido en el sistema penal y procesal, obviando casi siempre, en nombre de esta supuesta eficiencia, los derechos y libertades de los ciudadanos. No obstante, pese al teórico Estado Democrático y de Derecho en el que nos encontramos, han ido apareciendo manifestaciones inequívocas de este derecho, principalmente el de las vías de represión a todo lo calificado de terrorismo o que atente a la "seguridad nacional". Ciertamente, se aplica el viejo aforismo autoritario "ninguna libertad para los enemigos de la libertad”. Debemos ser conscientes y tener la esperanza de que éste otro período de ventaja del Derecho Penal, que lamentablemente se torna bastante degradante, y ante ello, uno tendrá que analizar y saber discernir de acuerdo a sus principios, lo que ahora es lo correcto en este contexto donde se mancilla el Estado de Derecho.

\section{BIBLIOGRAFÍA}

AZUELA G., Mariano. Derecho, Sociedad y Estado. Universidad Iberoamericana, México, 1996.

BINDER, Alberto. Justicia Penal y estado de Derecho. Ed. Ad Hoc. 2da. Edición. 2004.

BOBBIO, Norberto. Liberalismo y Democracia. Fondo de Cultura Económica. México. $1^{\mathrm{a}}$. Edición en español, 1992.

dictar los principios limitadores que conforman una política criminal democrática. La misma surgía en los años setenta también como una alternativa, y así era expresado por los grupos afines a la asociación de jueces Magistratura democrática que hablaban de un uso alternativo del derecho. Posteriormente, por intermedio de sus máximos representantes teóricos, comenzaría a hablarse de una política criminal garantista o minimalista (Ferrajoli 1986 y 1995, Baratta 1987, 1998 y 200o). Uno de los más importantes aciertos de estos planteamientos consistió en percatarse de que en realidad esa política criminal propuesta no era una «alternativa», sino que era una derivación lógica de los principios plasmados en la Constitución. (Rivera Beiras, Iñaki (coordinador) Politica criminal y sistema penal. Viejas y nuevas racionalidades punitivas. Anthropos editorial. Observatorio del sistema penal y los Derechos Humanos. Bracelona, 2005)

${ }^{23}$ De la Rúa, Jorge. El derecho penal democrático en la Argentina de hoy. Conferencia pronunciada en el XV Congreso latinoamericano, VII Iberoamericano y XI Nacional de Derecho Penal y Criminología, Universidad de Córdoba, Octubre de 2003. 
BOBBIO Norberto, Nicola Matteucci y Gianfranco Pasquino (comps.), Diccionario de política, vol. 1, Siglo XXI, México, 1988.

BOBBIO, Norberto. Igualdad y Libertad. Ed. Paidos, Barcelona, España, 1992.

CHOMSKY, Noam. Estados Canallas (El Imperio de la fuerza en los asuntos mundiales), Editorial, Paidos. Estado y Sociedad, Barcelona-España, 2001.

DE LA FUENTE, Virginia. Justicia Restaurativa y mediación penal. Burgos, España.

GÜNTHER, Jakobs. Cancio Meliá, M. Derecho Penal del enemigo. Editorial Aranzadi. 2006.

DÍAZ GARCÍA, Elías. Ética contra política. Ed. Centro de Estudios Constitucionales. España, 1990.

HERNÁNDEZ PLIEGO, Julio Antonio. Programa de Derecho Procesal Penal, Editorial Porrúa, México, 2002.

JACKOBS, Günter. Derecho Penal del enemigo. Thomson Civitas. Cuadernos Civitas. $1^{\text {a }}$ edición. 2003.

LOÏC Wacquant. Las cárceles de la miseria. Manantial, 2000, p. 192.

NIETO, Alejandro. El desgobierno judicial. Madrid, España, 2005.

LARRAURI, Elena. Herencia de la Criminología crítica. Ed. Siglo XXI, España. $3^{\text {a }}$ Edición. 2000.

MARX, Karl. Contribución a la crítica de la Economía Política. Siglo XXI.

PLANAS, Ricardo. Sánchez-Ostiz, Pablo. La crisis del Derecho penal contemporáneo. Barcelona, España. 2009.

RIVERA BEIRAS, Iñaki. (Coordinador) Política criminal y sistema penal. Viejas y nuevas racionalidades punitivas. Anthropos editorial. Observatorio del sistema penal y los Derechos Humanos. Bracelona, 2005).

VON HIRSCH, Andrew. Censurar y Castigar. Ed. Trotta, Madrid, España. 1998.

SITIOS WEB:

BLANCO ESCANDÓN, Celia. La prueba y los Derechos Humanos. Universidad Latina de América. Sede México (www.unla.edu.mx)

GONZÁLEZ, Daniel. Presidente Sala Casación. Costa Rica. Aplicación del Derecho Penal. (www.cienciaspenales.org)

La Crisis del Derecho Penal. www.juecesparalademocracia.com.es

DE LA RÚA, Jorge. El derecho penal democrático en la Argentina de hoy www.iuspenalismo. com.arg

SEGOVIA BERNABÉ, José Luis. La seguridad ciudadana y las víctimas: pistas éticas para humanizar el sistema penal. Artículo publicado en internet: http://www.iigov.org/seguridad/ 
OTROS TRABAJOS RELACIONADOS DEL AUTOR:

El delito y la burguesía. Análisis y publicación. 2010.

De vuelta a la mano dura. Artículo publicado. 07-2010.

La gran conspiración. Artículo publicado. 05-2010.

Estado, Globalización y Crimen organizado. Conferencia. o6-2010.

El urgente rediseño de la Policía Nacional Civil. o1-2010.

Crimen Organizado: Mitos y realidades. Artículo 03-2011.

La seguridad pública: una arquitectura social. Ensayo: Septiembre de 2011. 
